\title{
Intraday patterns in time-varying correlations among Central European stock markets ${ }^{1}$
}

\section{Introduction}

Existence and strength of relationships between various markets is an important issue examined in the economic and econometric literature in recent years. An increasing number of papers investigate short- and long-term linkages between returns and volatility on different stock exchanges. Such studies have been also performed for European stock markets, however, some of their results still lack consensus.

On the basis of daily data, Voronkova (2004) shows the existence of long-term linkages between European developed markets and three CEE stock markets. Additionally, Syriopoulos $(2004,2007)$ indicates that relationships between CEE and developed markets are stronger than among CEE countries themselves. On the other hand, Černy and Koblas (2005) as well as Égert and Kočenda (2007) do not find long-term relationships between intraday data of emerging and developed European stock markets.

Investigation of short-term relations, particularly Granger causality, leads to more common results. Hanousek et al. (2009) prove significant spillover effects on three CEE emerging markets, namely, Prague, Budapest and Warsaw. Their main indices influence each other, but they are also significantly influenced by returns of DAX, the main index of the Frankfurt Stock Exchange (FSE). The impact of FSE is even stronger than the impact of any of the emerging markets. Similar results are evidenced by Černý and Koblas (2005).

An important role of developed European markets for CEE emerging markets is also indicated by Égert and Kočenda (2007). On the basis of intraday data, they

\footnotetext{
* AGH University of Science and Technology, Faculty of Management, Department of Applications of Mathematics in Economics, e-mail: twojtow@agh.edu.pl

${ }^{1}$ Financial support for this paper from the National Science Centre of Poland [Research Grant DEC$-2012 / 05 / \mathrm{B} / \mathrm{HS} 4 / 00810]$ is gratefully acknowledged.
} 
show significant causalities between returns of CEE markets and causal relations from developed to emerging markets. An analogous pattern is observed for volatility. Interestingly, there is also evidence of the opposite relations from the volatility of BUX and WIG20 to that of DAX and UKX.

Interdependencies and co-movement of European stock markets have been also analyzed via multivariate GARCH models. Using CCC and STCCC models, Savva and Aslanidis (2010) show that the largest CCE markets (in Czech Republic, Hungary and Poland) exhibit stronger correlations with the euro area than smaller markets (such as Slovenia and Slovakia).

Syllignakis and Kouretas (2011) show that correlations between developed and emerging European markets have increased over time. The largest shift was caused by the 2007-2009 financial crisis. Also Gjika and Horvath (2013) confirm strong correlations between CEE markets and markets in the euro area. They show that the accession of CEE countries to the EU increased correlations. On the other hand, Égert and Kočenda (2011) show something opposite. They find very little positive time-varying correlations among intraday returns of BUX, PX50 and WIG20. Correlations between these markets and Western European stock markets also are very weak.

In this paper, we focus on relationships on an intraday scale. We study time-varying co-movement of prices on three Central European stock exchanges in Frankfurt, Vienna and Warsaw. These stock markets differ considerably. The Frankfurt Stock Exchange (FSE) is an example of a large developed market. In fact, it is one of the largest and the most important stock markets in Europe. Taking into account capitalization, the Vienna Stock Exchange (VSE) is about eighteen times smaller and the Warsaw Stock Exchange (WSE) is about eleven times smaller than $\mathrm{FSE}^{2}$. Despite these differences, the stock exchanges in Frankfurt and Vienna are both developed markets, while WSE is still seen as an emerging market. Hence, in this paper, we analyze relationships between large (FSE) and smaller stock markets (VSE and WSE) and also between developed (FSE and VSE) and emerging (WSE) stock markets. We study how these similarities and differences are reflected in the correlations between the markets and how they impact relationships between them.

We focus our attention on intraday patterns in conditional correlations between these stock markets. We describe and compare intraday correlations on different days of the week. We also analyze the impact of US macroeconomic news announcements on the strength of interrelations between stock exchanges

\footnotetext{
2 At the end of July 2015, capitalization of FSE was at the level of 1,625,718 mln $€$ compared to $147,417 \mathrm{mln} €$ of capitalization of WSE and 90,932 mln $€$ capitalization of VSE [Source: Federation of European Securities Exchanges, www.fese.eu].
} 
in Frankfurt, Vienna and Warsaw. Announcements of various US macroeconomic indicators were shown to be very important to European stock markets (Nikkinen and Sahlström, 2004; Harju and Hussain, 2011; Gurgul and Wójtowicz, 2014, 2015).

In order to analyze the evolution of time-varying intraday linkages between the markets, we apply the dynamic conditional correlation model (DCC) introduced by Engle (2002) to 5-minute data from the period between March 22, 2013 and July 31,2014 . It allows us to describe the evolution of short-time linkages between the stock markets under study as well as study intraday patterns in these relationships. During the estimation of the appropriate VAR model, we also examine the existence of Granger causalities between intraday returns. Results of this study will contribute to a better understanding of linkages between European stock markets, particularly in the CEE region.

The rest of the paper is organized as follows. In the next section we give short description of the DCC-GARCH models. In Section 3 we present and analyze in detail the data that we use in the empirical study. Section 4 contains the main empirical findings. A short summary concludes the paper.

\section{DCC-GARCH Models}

The dynamic conditional correlation (DCC) model introduced by Engle (2002) is one of the multivariate volatility models. It is a generalization of the constant conditional correlation (CCC) model of Bollerslev (1990). The DCC model allows a quite simple description of a time-varying variance-covariance matrix between return series. The model assumes that $\mathrm{n}$-dimensional vector of returns $r_{t}=\left(r_{1, t}, \ldots, r_{n, t}\right)^{\prime}$ has conditional multivariate normal distribution with zero mean and covariance matrix $H_{t}$, i.e. $r_{t} \mid \Omega_{t-1} \sim N\left(0, H_{t}\right)$, where $\Omega_{t-1}$ is the information set available at time $t-1^{3}$. In the DCC model, the covariance matrix can be decomposed into:

$$
H_{t}=D_{t} R_{t} D_{t}
$$

where $D_{t}=\operatorname{diag}\left(b_{1, t}, \ldots, b_{n n, t}\right)$ is a diagonal matrix of conditional standard deviations from univariate GARCH models and $R_{t}$ is the time-varying conditional correlation matrix of the following form:

$$
R_{t}=\operatorname{diag}\left(Q_{t}\right)^{-\frac{1}{2}} Q_{t} \operatorname{diag}\left(Q_{t}\right)^{-\frac{1}{2}}
$$

Dynamics of conditional correlations depends on the definition of $Q_{t}$.

\footnotetext{
${ }^{3}$ In practice, returns are replaced by residuals from the appropriate VAR model.
} 
In the DCC model with one lag, $Q_{t}$ evolves in time according to the formula (3):

$$
Q_{t}=(1-a-b) \bar{Q}+a \varepsilon_{t-1} \varepsilon_{t-1}^{\prime}+b Q_{t-1}
$$

where $\varepsilon_{t}=D_{t}^{-1} r_{t}$ are standardized returns, $\bar{Q}=E\left(\varepsilon_{t} \varepsilon_{t}^{\prime}\right)$ is the unconditional covariance of standardized returns, and $a$ and $b$ are nonnegative parameters such that $a+b<1$. If this condition is satisfied, $Q_{t}$ reverses back to $\bar{Q}$.

The parameters of the DCC-GARCH model are estimated via a two-step procedure. In the first step parameters of univariate GARCH models are estimated and returns are standardized. Then, $a$ and $b$ are estimated by maximizing the following likelihood function (Engle, 2002):

$$
L_{C}(\theta)=-\frac{1}{2} \sum_{t}\left(\ln \left|R_{t}\right|+\varepsilon_{t}^{\prime} R_{t}^{-1} \varepsilon_{t}\right)
$$

where $\theta=(a, b)$. Computation of $R_{t}$ in (4) (via computation of $Q_{t}$ ) is made recursively with starting value $Q_{0}$. When the DCC model is estimated on the basis of intraday data pooled together (like in this paper), the first value of $Q_{t}$ for each day is computed on the basis of the last value from the previous day.

In this paper, to take into account possible different dynamics of conditional correlations during days with and without US macroeconomic news announcements, we also consider a regime-switching DCC model with a covariance matrix of the following form:

$$
Q_{t}=\left\{\begin{array}{c}
Q_{t}^{\mathrm{I}}=\left(1-a_{\mathrm{I}}-b_{\mathrm{I}}\right) \bar{Q}_{\mathrm{I}}+a_{\mathrm{I}} \varepsilon_{t-1} \varepsilon_{t-1}^{\prime}+b_{\mathrm{I}} Q_{t-1} \\
Q_{t}^{\mathrm{II}}=\left(1-a_{\mathrm{II}}-b_{\mathrm{II}}\right) \bar{Q}_{\mathrm{II}}+a_{\mathrm{II}} \varepsilon_{t-1} \varepsilon_{t-1}^{\prime}+b_{\mathrm{II}} Q_{t-1}
\end{array}\right.
$$

where regimes I and II correspond to days without and with US macroeconomic news announcements, respectively, and $\bar{Q}_{\mathrm{I}}$ and $\bar{Q}_{\mathrm{II}}$ are unconditional covariances of standardized returns in each set of days. Additionally to the above dynamic structure, we assume that the initial value for each day is equal to $\bar{Q}_{\mathrm{I}}$ and $\bar{Q}_{\mathrm{II}}$, depending on the regime. With these assumptions, the sum in the likelihood function (4) can be separated into two sums: $L_{C}^{\mathrm{I}}(\theta)$ and $L_{C}^{\mathrm{II}}(\theta)$ for each regime, respectively. It follows that the estimation of such DCC model for days with news announcements does not depend on returns for days without news, and vice versa.

\section{Data}

The analysis presented in this paper is based on 5-minute returns of DAX, ATX, and WIG20, the main indices of stock exchanges in Frankfurt, Vienna, and Warsaw. The returns cover the period from March 22, 2013 to July 31, 2014. Data come from Bloomberg, the Vienna Stock Exchange and the Warsaw Stock Exchange. 
In the analysis, we consider only those returns from days when all of the markets were open. However, trading hours on the stock markets must be also taken into account, because the stock markets were open at different hours in the period under study. In 2013 and 2014, continuous trading started at 8:55 on VSE and at 9:00 on FSE and WSE. It ended at 16:50 (WSE), 17:30 (FSE), and 17:35 (VSE). Moreover, on FSE and VSE, there were intraday auctions at 13:00 and 12:00, respectively. Due to these differences in trading hours on the markets, and to the fact that the first 5-minute intraday return is observed at 9:05 and is accompanied by very high volatility, intraday relations are analyzed only in the common periods between 9:10 and 16:50. To model (or filter) intraday data, we must take into account the well-known fact that intraday volatility increases at the beginning and end of each trading session. Figure 1 shows a U-shaped pattern observed in intraday return volatility. It also shows a strong impact of news about the US economy, which is usually announced at 14:30. This strong impact of various US macroeconomic news announcements on the European stock market is widely confirmed by empirical works (e.g., Harju and Hussain, 2011; Gurgul and Wójtowicz, 2015).
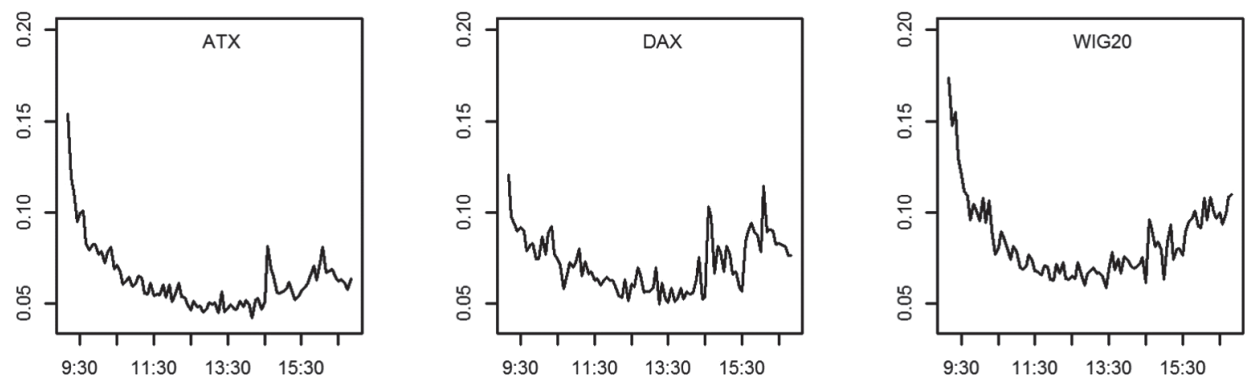

Figure 1. Cross-sectional standard deviations (in percentages) of 5-minute returns of ATX, DAX, and WIG20

To deal with periodic patterns in volatility as well as the impact of US news announcements, we apply a method of Flexible Fourier Form (FFF) adopted to intraday data by Andersen and Bollerslev (1997). Specifially, we decompose 5-min returns $R_{t, n}$ at time $n$ on day $t$ as:

$$
R_{t, n}-E\left(R_{t, n}\right)=s_{t, n} \sigma_{t, n} Z_{t, n}
$$

where $Z_{t, n}$ is i.i.d $(0,1), \sigma_{t, n}$ is a daily volatility factor and $s_{t, n}$ is an intraday (diurnal) seasonal component such that $\ln \left(s_{t, n}^{2}\right)$ can be estimated from the following FFF regression (6). 


$$
\begin{aligned}
2 \ln \frac{\left|R_{t, n}-\bar{R}\right|}{\left(\widehat{\sigma}_{t} N^{0.5}\right)}= & c+\sum_{k=1}^{D} \lambda_{k} I_{k}(t, n)+\delta_{1} \frac{n}{N_{1}}+\delta_{2} \frac{n^{2}}{N_{2}}+ \\
& +\sum_{p=1}^{P}\left(\delta_{c, p} \cos \left(\frac{2 \pi p}{N} n\right)+\delta_{s, p} \sin \left(\frac{2 \pi p}{N} n\right)\right)+\varepsilon_{t, n}
\end{aligned}
$$

where refers to the number of returns per day (here $N=94), N_{1}=\frac{N+1}{2}$, $N_{2}=\frac{(N+1)(N+2)}{6}, I_{k}(t, n)$ allows for the inclusion of weekdays and US macroeconomic news announcement dummies. In this paper, we use six dummy variables to model intraday volatility up to a half an hour after news announcements. The daily variance component $\sigma_{t, n}$ is approximated by volatility forecasts from the appropriate GARCH model with skewed Student's $t$-distribution constructed for daily returns.

On the basis of literature (e.g., Nikkinen et al., 2006; Harju and Hussain, 2011; Gurgul and Wójtowicz, 2014, 2015), we include regression dummy variables in the FFF describing the impact of announcements of the following US macroeconomic indicators: Consumer Price Index (CPI), Producer Price Index (PPI), Industrial Production (IP), Retail Sales (RS), Durable Goods Orders (DGO), Nonfarm Payrolls (NFP), Existing Home Sales (EHS), Housing Starts (HS), and New Home Sales (NHS). The majority of them (CPI, PPI, RS, DGO, NFP, and HS) are released at 8:30 $\mathrm{EST}^{4}(14: 30 \mathrm{CET})$. EHS and NHS are released at 10:00 EST (16:00 CET). Only IP is released at 9:15 EST (15:15 CET). Due to the differences in the introduction of Daylight Saving Time in the US and Europe, some of announcements reach European stock markets one hour earlier in March and October; i.e., at 13:30 CET, 15:00 CET, and 14:15 CET, respectively.

\section{Empirical Results}

We start the analysis with a computation of unconditional Spearman correlations between the returns of ATX, DAX, and WIG20 in the entire period of March 2013 - July 2014. This will be a background for further analysis of time-varying intraday co-movements. Results in Table 1 give very general information about the average strength of relations between the indices. All computed values of correlation coefficients are significantly positive and indicate rather mild interdependencies between the markets, particularly between FSE and VSE. The smallest, but still significant, correlation is between ATX and WIG20. This is in contrast

\footnotetext{
${ }^{4}$ EST - Eastern Standard Time; CET - Central European Time
} 
with the results of Égert and Kočenda (2011) of very weak intraday correlations between CEE markets and European developed markets.

Table 1

Spearman correlations between 5-min returns of ATX, DAX, and WIG20

\begin{tabular}{|c|c|c|c|}
\cline { 2 - 4 } \multicolumn{1}{c|}{} & ATX-DAX & ATX-WIG20 & DAX-WIG20 \\
\hline Correlation & 0.336 & 0.154 & 0.254 \\
\hline
\end{tabular}

More in-depth analysis of intraday relations is made on the basis of the DCC-GARCH model described in Section 2. First, we estimate the trivariate VAR model to filter out autocorrelation observed in intraday returns. On the basis of the Akaike information criterion, we chose the VAR model with 7 lags. Its estimation provides a perfect opportunity to study Granger causalities between the stock markets. The significance of past DAX returns in equations for WIG20 and ATX returns ${ }^{5}$ indicates a strong one-directional intraday Granger causality from the stock exchange in Frankfurt to markets in Vienna and Warsaw. This is in line with previous results indicating the strong impact of large developed European markets on the stock exchanges in the CEE region. Moreover, it indicates that such an impact is observed not only for emerging markets but also for mature markets (like VSE).

To model the conditional variance of the univariate series of residuals from the VAR model, we first remove diurnal periodicity from the 5-min return volatility. The application of FFF confirms the conclusions from Figure 1 regarding a very high variance of returns at the beginning of the trading session. It also indicates a strong and significant impact of US macroeconomic news announcements on intraday volatility. For each index, dummy variables are significant in the first 5-minute period after news announcements (irrespective of the time of the announcement). This is clearly visible in Figure 2, where we present examples of intraday volatility components for days with US announcements at 14:30. After removing the daily and intraday seasonality components of volatility we filter out 5-min returns with $\operatorname{GARCH}(1,1)$ models with conditional skewed Student's $t$-distribution.

Time-varying correlations of the standardized residuals are modeled via the DCC model with 1 lag and multivariate normal distribution. The estimation results reported in Table 2 are typical for a financial time series: a small value of and a value of significant and close to 1 indicate very strong persistence of timevarying intraday correlations between ATX, DAX, and WIG20.

\footnotetext{
5 The F statistics in the significance tests of joint impact of historical DAX returns in equations for ATX and WIG20 returns is significant at any reasonable level.
} 

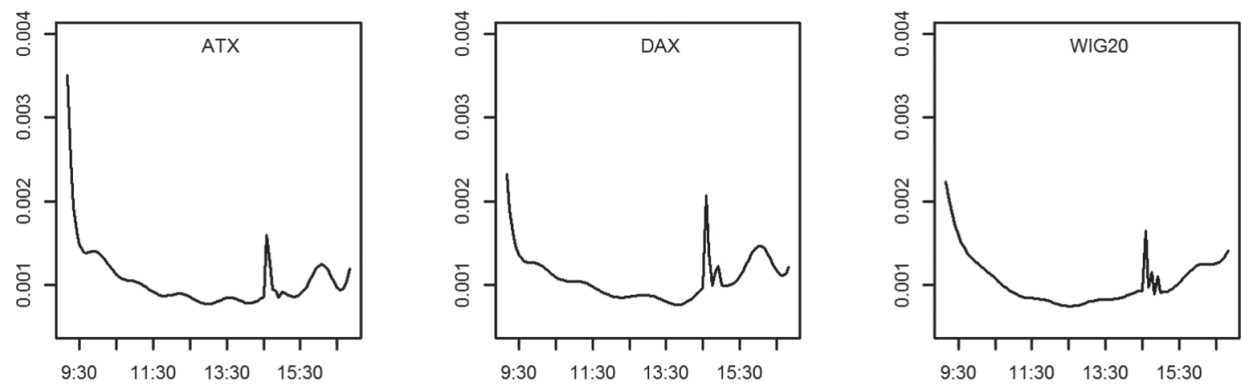

Figure 2. Intraday seasonal component $s_{t, n}$ of ATX, DAX, and WIG20 on days with US macroeconomic news announcement at 14:30

Table 2

Parameters of DCC-GARCH model for 5-minute returns of ATX, DAX, and WIG20

\begin{tabular}{|c|c|c|c|c|}
\cline { 2 - 5 } \multicolumn{1}{c|}{} & Estimate & Std. error & $\boldsymbol{t}$-statistics & $\boldsymbol{p}$-value \\
\hline$a$ & 0.0068 & 0.0071 & 0.956 & 0.339 \\
\hline$b$ & 0.9894 & 0.0147 & 67.46 & 0 \\
\hline
\end{tabular}

The strength and evolution of interrelations between the stock markets is captured by intraday conditional correlations (the off-diagonal elements of matrices $R_{t}$ ) presented in Figure 3. They are in line with values of Spearman correlations in Table 1. In general, intraday correlations vary around their unconditional values in the period under study. The strongest relation is observed between ATX and $\mathrm{DAX}$, where conditional correlations change between 0.1 and 0.6. The weakest relations are observed between ATX and WIG20, where intraday correlations are smaller than 0.4 during the whole period. Changes in intraday relations between the markets are similar. In the first part of the period, intraday correlations decrease, while the lowest correlations are generally observed in the central part of the sample.

Additionally, to the analysis of the whole period, we study changes in correlations during the trading day. For each time $t$ from set 9:10, 9:15, .., 16:50, we compute cross-sectional average $\bar{R}_{t, i j}$ of conditional correlations between indices $i$ and $j$ at time $t$. Changes in the averages presented in Figure 4 indicate the existence of an intraday pattern in the relationships between stock markets. In general, correlations are stronger at the beginning and at the end of a trading session, while they are weaker in the middle of the day. It is important to 
note that conditional correlations start to increase about $14: 30$; i.e., when the majority of important US data is announced and the US derivative market opens. The averages reach the highest values in the final part of the trading session (around 16:30). These observations lead to the question about the impact of US data announcements on the strength of interrelations between European stock markets.
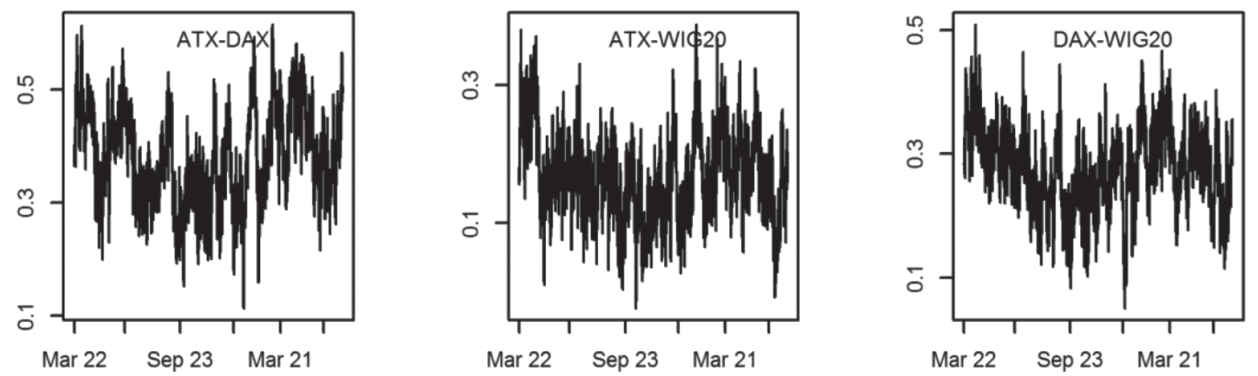

Figure 3. Intraday conditional correlations between ATX, DAX, and WIG20 during the period of March 22, 2013 - July 31, 2014
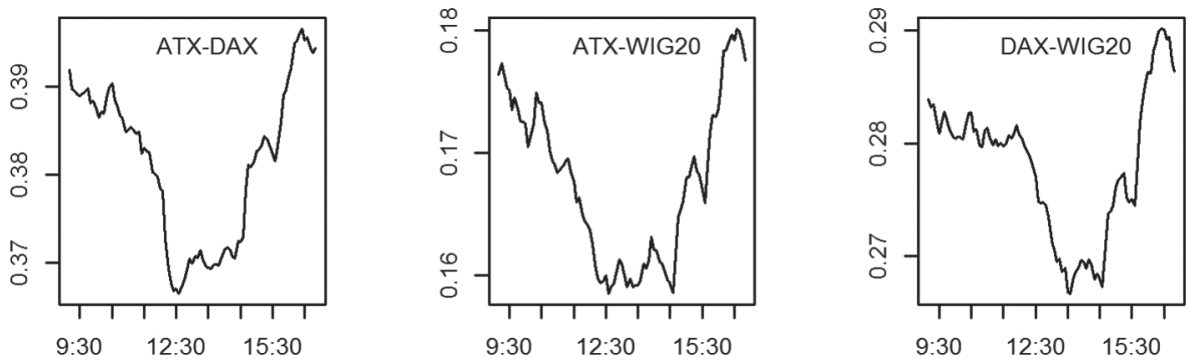

Figure 4. Cross-sectional averages of conditional correlations between ATX, DAX, and WIG20

\subsection{Correlations during days with US macroeconomic news announcements}

As a first insight into relationships during days with and without US macroeconomic news, we compare Spearman correlations during these days. Values in Table 3 indicate that stock markets are more closely related when important news about the US economy is to be announced. During these days, correlation coefficients are about 11-18\% higher than during days without scheduled information from the US. 
Table 3

Spearman correlations between 5-min returns of ATX, DAX, and WIG20 during days with and without US macroeconomic news announcements

\begin{tabular}{|l|c|c|c|}
\cline { 2 - 4 } \multicolumn{1}{c|}{} & ATX-DAX & ATX-WIG20 & DAX-WIG20 \\
\hline Days without announcements & 0.319 & 0.147 & 0.246 \\
\hline Days with announcements & 0.376 & 0.170 & 0.273 \\
\hline
\end{tabular}

To compare correlations between the markets during days when US data is announced as well as days without such important announcements, we estimate a regime-switching DCC model. Estimation results are reported in Table 4 . The values of $a_{\mathrm{I}}$ and $b_{\mathrm{I}}$ are close to the values of $a$ and $b$ from Table 2 . In fact, the differences between the respective parameters are insignificant. But, when we compare the right panel of Table 4 with Table 2 , we can notice that $b_{\text {II }}$ is significantly smaller than $b$ for the whole sample. Moreover, $a_{\mathrm{II}}$ and $b_{\mathrm{II}}$ are significantly different from $a_{\mathrm{I}}$ and $b_{\mathrm{I}}$, respectively. This confirms that the dynamics of intraday conditional correlations during days with and without US news announcements differ significantly. When US news is announced, the conditional correlation is less persistent, and the impact of previous returns is a little stronger than during days without new information.

Table 4

Parameters of regime switching DCC-GARCH models for ATX, DAX, and WIG20 during days with and without US macroeconomic news announcements.

\begin{tabular}{|c|c|c|c|c|c|c|c|}
\hline \multirow{2}{*}{$\begin{array}{l}\text { Para- } \\
\text { meter }\end{array}$} & \multicolumn{3}{|c|}{ Days without US news } & \multirow{2}{*}{$\begin{array}{l}\text { Param- } \\
\text { eter }\end{array}$} & \multicolumn{3}{|c|}{ Days with US news } \\
\hline & Estimate & Std. error & $p$-value & & Estimate & Std. error & $p$-value \\
\hline$a_{\mathrm{I}}$ & 0.008 & 0.0007 & 0 & $a_{\mathrm{II}}$ & 0.014 & 0.0013 & 0 \\
\hline$b_{\text {I }}$ & 0.979 & 0.0035 & 0 & $b_{\mathrm{II}}$ & 0.958 & 0.0055 & 0 \\
\hline
\end{tabular}

As before, we compare not only the estimated values but also the intraday seasonality of conditional correlations during both types of days. In Figure 5, we can observe that the cross-sectional averages of conditional correlations during days with announcements are above the averages from days without announcements during the whole trading day. To be more precise, for each time $t$, we use the Kruskal-Wallis test to compare the distributions of the both groups of conditional correlations. The shadowed regions in Figure 5 indicate $t$ for which the null hypothesis about equality of distributions cannot be rejected. The clearest interpretation is for ATX and DAX where, for each time $t$, the conditional 
correlations during days with announcements are significantly greater than correlations during days without US macroeconomic news. For pairings ATX-WIG20 and DAX-WIG20, such significant differences are visible at the beginning of the trading session (until 10:50 for ATX-WIG20 or until 12:20 for DAX-WIG20) and at the end of the trading session (after 14:40 for ATX-WIG20 and after 14:00 for DAX-WIG20). A comparison of the left and right panels in Figure 5 shows the difference in relations of stock exchanges in Warsaw and Vienna with the stock market in Frankfurt. Scheduled US macroeconomic news announcements significantly strengthen the relationships between VSE and FSE over the whole day. In the case of WSE, an increase in correlation is visible in the presence of new information.
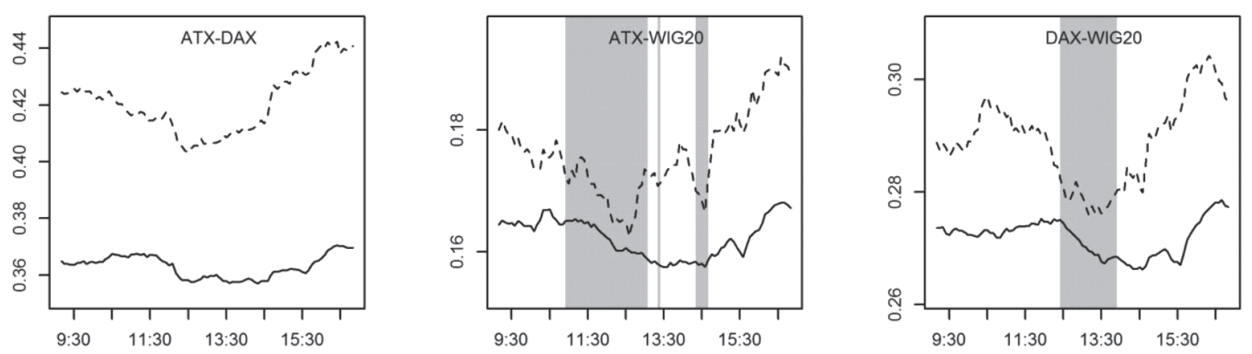

Figure 5. Cross-sectional averages of conditional correlations between ATX, DAX, and WIG20 during days with US macroeconomic news announcements (dashed lines) and without (solid lines)

\subsection{Correlations in different days of the week}

In order to compare the heterogeneity of interrelations between stock markets in Frankfurt, Vienna, and Warsaw throughout the week, we compare correlations between these markets on different days of the week. From Table 5 (where we report unconditional Spearman correlations), we can notice that the lowest correlations are at the beginning of the week (on Mondays for correlations with DAX and on Tuesdays for correlations between ATX and WIG20). The highest correlations are observed on Wednesdays (DAX-WIG20) or Thursdays (ATX-DAX and ATX-WIG20). These differences confirm that the strength of intraday interrelations between the stock markets under study may depend on the day of the week. They also suggest the existence of the 'day-of-the-week effect' in conditional correlations. To examine this, we estimate a regime-switching DCC model with five regimes corresponding to the days of the week. In the last two columns of Table 5, we report estimated values of model parameters $a_{\mathrm{Mon}}, \ldots, a_{\mathrm{Fri}}$ and $b_{\mathrm{Mon}}, \ldots, b_{\mathrm{Fri}}$. All of them are significantly greater than 0 at the $1 \%$ level. 
Table 5

Spearman correlations between 5-min returns of ATX, DAX, and WIG20 on different days of the week during days with and without US macroeconomic news announcements

\begin{tabular}{|l|c|c|c|c|c|}
\cline { 2 - 6 } \multicolumn{1}{c|}{} & ATX-DAX & ATX-WIG20 & DAX-WIG20 & $\boldsymbol{a}$ & $\boldsymbol{b}$ \\
\hline Mondays & 0.322 & 0.144 & 0.222 & 0.0081 & 0.9845 \\
\hline Tuesdays & 0.327 & 0.137 & 0.245 & 0.0070 & 0.9649 \\
\hline Wednesdays & 0.333 & 0.165 & 0.272 & 0.0102 & 0.9708 \\
\hline Thursdays & 0.352 & 0.167 & 0.258 & 0.0121 & 0.9705 \\
\hline Fridays & 0.346 & 0.156 & 0.271 & 0.0118 & 0.9662 \\
\hline
\end{tabular}

Similar to section 4.1, we also compare cross-sectional distributions of intraday conditional correlations for each day of the week. As before, at each time $t$, we apply the Kruskal-Wallis test to verify the significance of the difference between the distributions of conditional correlations from different days of the week.
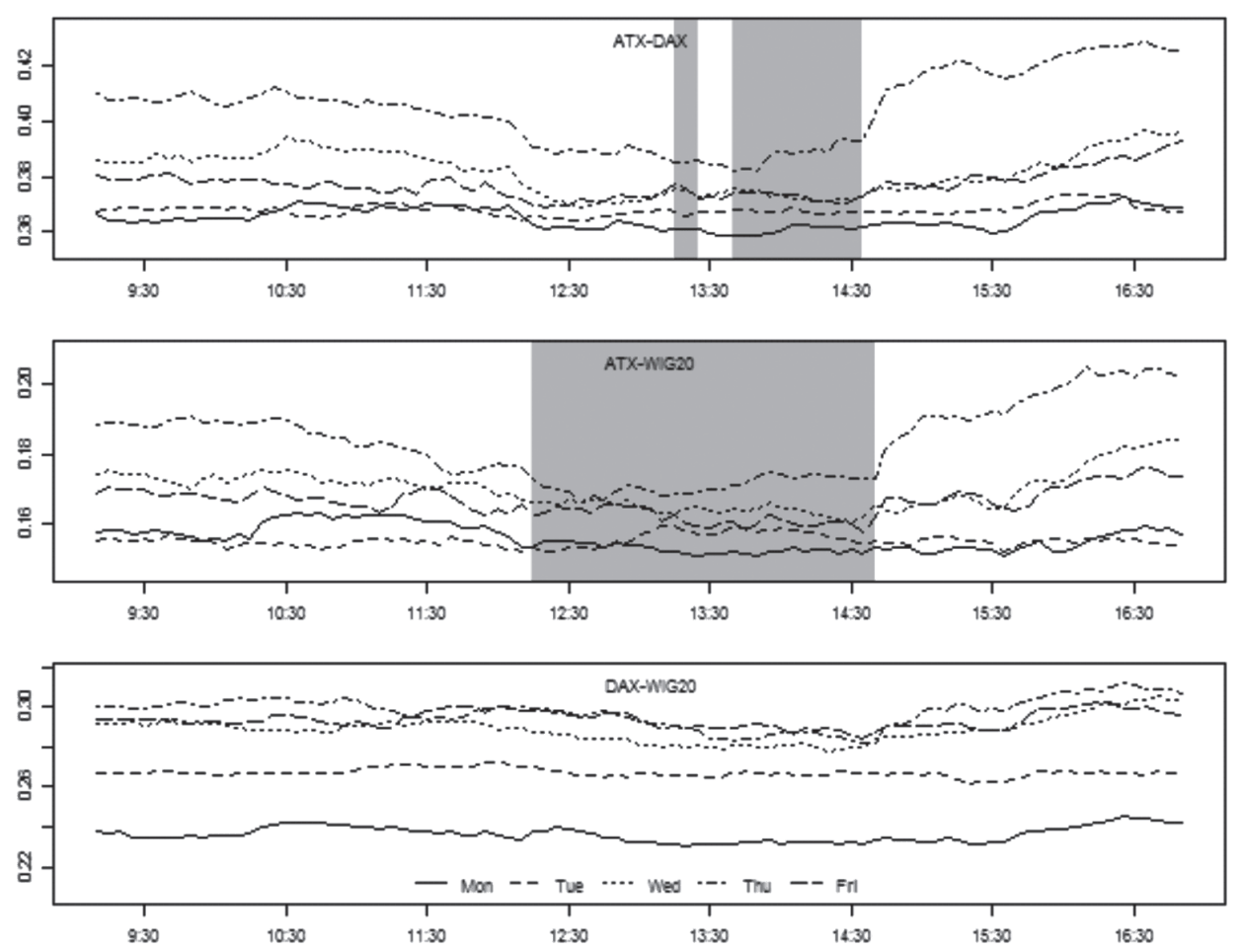

Figure 6. Cross-sectional averages of conditional correlations between ATX, DAX, and WIG20 on different days of the week 
The shaded regions in Figure 6 indicate values of $t$ where the null hypothesis is not rejected. From the bottom panel of Figure 6, we can conclude that the relationships between DAX and WIG20 strongly depends on the day of the week. It is significantly the weakest in Mondays than on other days. These differences are significant for each time $t$ during the trading session. This is similar to the impact of US macroeconomic news announcements on the correlation between ATX and DAX. In the case of correlations with ATX, the rejection of the null hypothesis in the morning and afternoon is caused by significantly higher correlations on Thursdays rather than by low correlations on Mondays. This indicates a difference in the relationships between the stock exchange in Frankfurt and VSE and WSE. The strength of relationships between WSE and FSE is very weak in Mondays, while relationships on Wednesdays, Thursdays, and Fridays are similar.

\section{Conclusions}

In this paper, we analyze and compare interrelations between stock markets in Frankfurt, Vienna, and Warsaw. The analysis is performed on the basis of 5-minute data from the period of March 22, 2013 - July 31, 2014. The application of an appropriate VAR model confirms the previous results about Granger causality running from a large, developed stock exchange in Frankfurt to stock markets in Central and Eastern Europe. Further analysis indicates significant intraday correlations between the stock markets under study. The strongest relationships is observed between both developed markets in Frankfurt and Vienna. The application of DCC models shows the difference between intraday relations of ATX and WIG20 with DAX. US macroeconomic news announcements have a stronger impact on relationships between stock markets in Vienna and Frankfurt, while the day-of-the-week effect is more pronounced in the relationships between stock exchanges in Warsaw and Frankfurt.

\section{References}

[1] Andersen, T. and Bollerslev, T. (1997) 'Intraday periodicity and volatility persistence in financial markets', Journal of Empirical Finance, vol. 4, pp. 115-158.

[2] Bollerslev, T. (1990) 'Modelling the Coherence in Short-Run Nominal Exchange Rates: A Multivariate Generalized ARCH Model', The Review of Economics and Statistics, vol. 72, No. 3, pp. 498-505.

[3] Černý, A. and Koblas, M. (2005) 'Stock Market Integration and the Speed of Information Transmission: The Role of Data Frequency in Cointegration and Granger Causality Tests', Journal of International Business and Economics, vol. 1, pp. 110-120. 
[4] Engle, R.F. (2002) 'Dynamic Conditional Correlation', Journal of Business and Economic Statistics, vol. 20, No. 3, pp. 339-350.

[5] Égert, B. and Kočenda, E. (2007) 'Interdependence between Eastern and Western European Stock Markets: Evidence from Intraday Data', Economic Systems, vol. 31, No. 2, pp. 184-203.

[6] Égert, B. and Kočenda, E. (2011) 'Time-varying synchronization of European stock markets', Empirical Economics, vol. 40, No. 2, pp. 393-407.

[7] Gjika, D. and Horváth, R. (2013) 'Stock Market Comovements in Central Europe: Evidence from Asymmetric DCC Model', Economic Modelling, vol. 33, pp. 55-64.

[8] Gurgul, H. and Wójtowicz, T. (2014) 'The impact of US macroeconomic news on the Polish stock market. The importance of company size to information flow', Central European Journal of Operations Research, vol. 22, pp. 795-817.

[9] Gurgul, H. and Wójtowicz, T. (2015) 'The Response of Intraday ATX Returns to U.S. Macroeconomic News', Finance a úvěr - Czech Journal of Economics and Finance, vol. 65, No. 3, pp. 230-253.

[10] Hanousek, J., Kočenda, E. and Kutan, A.M. (2009) 'The reaction of asset prices to macroeconomic announcements in new EU markets: evidence from intraday data', Journal of Financial Stability, vol. 5, No. 2, pp. 199-219.

[11] Harju, K. and Hussain, S.M. (2011) 'Intraday seasonalities and macroeconomic news announcements', European Financial Management, vol. 17, pp. 367-390.

[12] Nikkinen, J. and Sahlström, P. (2004) 'Scheduled Domestic and US Macroeconomic News and Stock Valuation in Europe', Journal of Multinational Financial Management, vol. 14, pp. 201-245.

[13] Nikkinen, J., Omran, M., Sahlström, M. and Äijö, A. (2006) 'Global stock market reactions to scheduled U.S. macroeconomic news announcements', Global Finance Journal, vol. 17(1), pp. 92-104.

[14] Savva, C.S. and Aslanidis, C. (2010) 'Stock Market Integration between New EU Member States and the Eurozone', Empirical Economics, vol. 39, No. 2, pp. 337-351.

[15] Syllignakis, M.N. and Kouretas, G.P. (2011) 'Dynamic Correlation Analysis of Financial Contagion: Evidence from the Central and Eastern European Markets', International Review of Economics \& Finance, vol. 20, No. 4, pp. 717-732.

[16] Syriopoulos, T. (2004) 'International portfolio diversification to Central European stock markets', Applied Financial Economics, vol. 14, pp. 1253-1268.

[17] Syriopoulos, T. (2007) 'Dynamic linkages between emerging European and developed stock markets: Has the EMU any impact?', International Review of Financial Analysis, vol. 16, No. 1, pp. 41-60.

[18] Voronkova, S. (2004) 'Equity Market Integration in Central European Emerging Markets: A Cointegration Analysis with Shifting Regimes', International Review of Financial Analysis, vol. 13, No. 5, pp. 633-647. 